Article

\title{
Extraction of Fucoxanthin from Raw Macroalgae excluding Drying and Cell Wall Disruption by Liquefied Dimethyl Ether
}

\author{
Hideki Kanda ${ }^{1,2, *}$, Yuichi Kamo ${ }^{1}$, Siti Machmudah ${ }^{1,3}$, Wahyudiono ${ }^{1}$ and Motonobu Goto ${ }^{2}$ \\ 1 Department of Chemical Engineering, Nagoya University, Furo-cho, Chikusa-ku, \\ Nagoya 464-8603, Japan; E-Mails: kamo.yuuichi@d.mbox.nagoya-u.ac.jp (Y.K.); \\ machmudah.siti@d.mbox.nagoya-u.ac.jp (S.M.); wahyudiono@b.mbox.nagoya-u.ac.jp (W.) \\ 2 Japan Science and Technology Agency, Chiyoda, Tokyo 102-0076, Japan; \\ E-Mail:mgoto@nuce.nagoya-u.ac.jp \\ 3 Department of Chemical Engineering, Sepuluh Nopember Institute of Technology, \\ Kampus ITS Sukolilo, Surabaya 60111, Indonesia \\ * Author to whom correspondence should be addressed; E-Mail: kanda@nuce.nagoya-u.ac.jp; \\ Tel./Fax: +81-52-789-5484.
}

Received: 19 November 2013; in revised form: 6 January 2014 / Accepted: 26 March 2014 / Published: 30 April 2014

\begin{abstract}
Macroalgae are one of potential sources for carotenoids, such as fucoxanthin, which are consumed by humans and animals. This carotenoid has been applied in both the pharmaceutical and food industries. In this study, extraction of fucoxanthin from wet brown seaweed Undaria pinnatifida (water content was 93.2\%) was carried out with a simple method using liquefied dimethyl ether (DME) as an extractant in semi-continuous flow-type system. The extraction temperature and absolute pressure were $25^{\circ} \mathrm{C}$ and $0.59 \mathrm{MPa}$, respectively. The liquefied DME was passed through the extractor that filled by $U$. pinnatifida at different time intervals. The time of experiment was only $43 \mathrm{~min}$. The amount of fucoxanthin could approach to $390 \mu \mathrm{g} / \mathrm{g}$ dry of wet $U$. pinnatifida when the amount of DME used was $286 \mathrm{~g}$. Compared with ethanol Soxhlet and supercritical $\mathrm{CO}_{2}$ extraction, which includes drying and cell disruption, the result was quite high. Thus, DME extraction process appears to be a good method for fucoxanthin recovery from U. pinnatifida with improved yields.
\end{abstract}

Keywords: dimethyl ether; supercritical $\mathrm{CO}_{2}$; fucoxanthin; wet extraction 


\section{Introduction}

Undaria pinnatifida is consumed as one of the most popular, traditional seaweeds, particularly in East Asian countries such as Japan and Korea. In the current food industry, U. pinnatifida is mainly manufactured in the form of dry particles by using coarse grinder. Dry U. pinnatifida particles swell in hot water, and are used as an ingredient in popular foods such as bean paste soup in Japan. The main functional constituent of $U$. pinnatifida is fucoxanthin [1,2], which is a xanthophylls pigment contained in the chloroplasts of brown macroalgae. Fucoxanthin also had ability to exert effects in humans, such as antidiabetic effect [3,4], cholesterol metabolism [5,6], anti-obesity effect [1], anti-oxidant properties [2,7,8], anti-proliferative effect on cancer cells [9,10], and anti-inflammatory [11]. Extraction of bioactive compounds from macroalgae has great potential and its applications will continue to grow in the following years [12]. Pressurized solvent extraction has been used, for example, to isolate carotenoids from brown macroalgae, such as Eisenia bicyclis [13], Cystoseira abies-marina, and Himanthalia elongata [14]. The results showed that ethanol at high temperatures provide high recoveries of fucoxanthin and other oxygenated carotenoids. Moreover, many studies of biomaterials production have reported that cell disruption is a significant important factor to extract organic components contained in cells. For example, microwave assisted extraction of fucoxanthin from $U$. pinnatifida cells [15-18]. However, fucoxanthin exhibited sensitivity towards some factors such as light and $\mathrm{pH}$, the least stable in acidic $\mathrm{pH}$ condition and higher concentration of ascorbic acid supplementation exerted stabilization role on fucoxanthin [19], and carotenoids are thermally decomposed in hot-drying.

Liquefied DME was used as an extractant to enhance extraction of fucoxanthin from U. pinnatifida. DME is the simplest form of ether [20], with the following characteristics. (i) DME has a low normal boiling point $\left(-24.8^{\circ} \mathrm{C}\right)[21]$, therefore, DME is not present in the final products at normal temperatures; (ii) Relative permittivity of DME is 1.08 and 5.34 at $30.5^{\circ} \mathrm{C}$, in gaseous and liquid states, respectively. Liquefied DME has high affinity to oily substances [22] and partial miscibility with water [23]; (iii) DME has been approved as a safe extraction solvent for the production of foodstuff and food ingredients by the European Food Safety Authority (EFSA) [24], by the Food Standards Australia New Zealand, and by the United States [25]. The panels of EFSA consider the intended use of dimethyl ether as an extraction solvent to remove fat from animal protein raw materials. Considering (a) that the defatted animal protein is submitted to vacuum which assures that most of the volatile dimethyl ether is eliminated from final animal protein products (b) that the maximum residual limit of dimethyl ether is of $9 \mu \mathrm{g} / \mathrm{kg}$ of extracted animal proteins and (c) that these proteins are used at a level of up to $2 \%$ in the final food, the Panel considered that there is no safety concern [24]; (iv) DME exhibits resistance to autoxidation, unlike other alkyl ethers [26]. Owing to these characteristics, the authors successfully extracted lipids and water from wet vegetal biomasses by liquefied DME. In the DME-based extraction technique, drying, cell disruption, and heating of solvent were not needed to improve extraction yields [27].

In this work, the effect of pressure, temperature, and ethanol as co-solvent on the recovery of fucoxanthin from $U$. pinnatifida using supercritical $\mathrm{CO}_{2}$ would be also presented. However, the lipids content in the extract is not presented, although supercritical $\mathrm{CO}_{2}$ is well known as an effective technique to extract lipids. Several experimental studies of extraction by supercritical $\mathrm{CO}_{2}$ have 
reported that supercritical $\mathrm{CO}_{2}$ extraction is an environmentally-friendly for lipids and carotenoids extraction from micro- and macroalgae. Mendes et al. carried out supercritical $\mathrm{CO}_{2}$ extraction of carotenoids and other lipids on whole and crushed Chlorella vulgaris [28]. Machmudah et al. and Kitada et al. also extracted carotenoids and astaxanthin from microalgae of Haematococcus pluvialis [29] and $C$. vulgaris [30] with supercritical $\mathrm{CO}_{2}$. The results showed that supercritical $\mathrm{CO}_{2}$ is more selective for carotenes than the usual organic liquid extraction and it is preferred for handling temperature-sensitive molecules. Extraction using supercritical $\mathrm{CO}_{2}$ with ethanol as the co-solvent has also been performed with brown seaweed at 0.8 to $30 \mathrm{MPa}$ and 303 to $333 \mathrm{~K}$ [31]. The significant amount of oil from brown seaweed was extracted within $50 \mathrm{~min}$. Roh et al. reported that the oil extraction yield of brown seaweed was high at higher pressure, and the amounts of fucoxanthin extracted at $20 \mathrm{MPa}$ of $\mathrm{CO}_{2}$ pressure and $323 \mathrm{~K}$ of extraction temperature showed much higher than other extraction conditions [31]. As a comparison, the extraction yield from $U$. pinnatifida was also tested by using the conventional solvent ethanol with a Soxhlet extractor. As explained before that fucoxanthin has been implicated as important dietary nutrients having antioxidant potential. It is one of the reasons why some researchers had evaluated the in vitro antioxidant activity of fucoxanthin extracted from algae. For example, Roh et al. suggested that fucoxanthin content should be considered as an important feature of brown seaweed, as some of its nutritive and pharmacological effects could be attributed to their presence in plant material [31]. Billakanti et al. also reported that the yield of fucoxanthin from U. pinnatifida could be improved by using an enzyme-assisted extraction process followed by DME extraction. The results showed that extraction of fucoxanthin from $U$. pinnatifida using supercritical $\mathrm{CO}_{2}$ with ethanol as a co-solvent and enzymatic pre-treatment followed by DME extraction have no effect on the fucoxanthin properties [20]. Therefore, in this study the antioxidant activity of fucoxanthin was not conducted. Isolation and purification of fucoxanthin from extraction products were also not carried out.

\section{Results and Discussion}

\subsection{Ethanol Soxhlet Extraction}

It was well known that the extraction of organic compounds using a range of organic solvents from matrices (soils, sewage sludges, vegetables, and plants) has historically been carried out by using Soxhlet extraction. The apparatus for Soxhlet extraction consisted of a solvent reservoir, extractor body, an electric heat source and a water-cooled reflux condenser. Since the temperature plays a significant role for extraction, increased temperatures can disrupt the strong solute-matrix interactions caused by van der Waals forces, hydrogen bonding, and dipole attractions of the solute molecules and active sites on the matrix [32]. Therefore, the use of ethanol as an extract solvent at elevated temperature is enhanced solubility and mass transfer effects, and disruption of surface equilibria. Kim et al. reported that ethanol provided the best fucoxanthin extraction yield from Phaeodactylum tricornutum (15.71 mg/g freeze-dried sample weight) [33]. They explained that fucoxanthin content in the extracts produced by the different methods was quite constant $(15.42-16.51 \mathrm{mg} / \mathrm{g}$ freeze-dried sample weight) but increased steeply based on the percentage of ethanol in water, emphasizing the importance of ethanol in the extraction. Kanazawa et al. also reported that $191 \mu \mathrm{g} / \mathrm{g}$ wet sample weight was extracted from Laminalia japonica with ethanol at $40{ }^{\circ} \mathrm{C}$ [34]. 
In this work, by using ethanol solvent, $50 \mu \mathrm{g}$ of fucoxanthin has been extracted from U. pinnatifida $6 \mathrm{~g}$. This result might be due to some contribution from the physical properties of $U$. pinnatifida. The size of $U$. pinnatifida was $0.5-3 \mathrm{~cm}$ directly fed without pre-treatment. The particle size is other factors that high influence the mass transfer during Soxhlet process. Bigger particles present lower ratios of surface area to volume. Conversely, smaller particles present higher ratios of surface area to volume, which enhance the contact between solvent and solid matrix and diminish the diffusion path of the particle to reach the surface, resulting in a high extraction yield. In addition, there was possibility that the degradation of fucoxanthin in ethanol solution might have occurred during Soxhlet extraction process $(12 \mathrm{~h})$.

\subsection{Liquefied DME Extraction}

As shown in Figure 1, fucoxanthin has been extracted from $U$. pinnatifida with small amount of DME (24 g). It should be noted that the lipids content in the extract is not determined. The increasing amount of DME used was followed by increasing the amount of fucoxanthin extracted. When the amount of DME used was $286 \mathrm{~g}$ (at the last time point of extraction process), the residue of the $U$. pinnatifida was almost perfectly dewatered as like as such kind of dry paper. The color of $U$. pinnatifida was also changed to light green color. The amount of fucoxanthin could approach up to $390 \mu \mathrm{g} / \mathrm{g}$ dry of $U$. pinnatifida at this point.

Figure 1. Yield of fucoxanthin in the extract obtained from wet $U$. pinnatifida by liquefied dimethyl ether (DME).

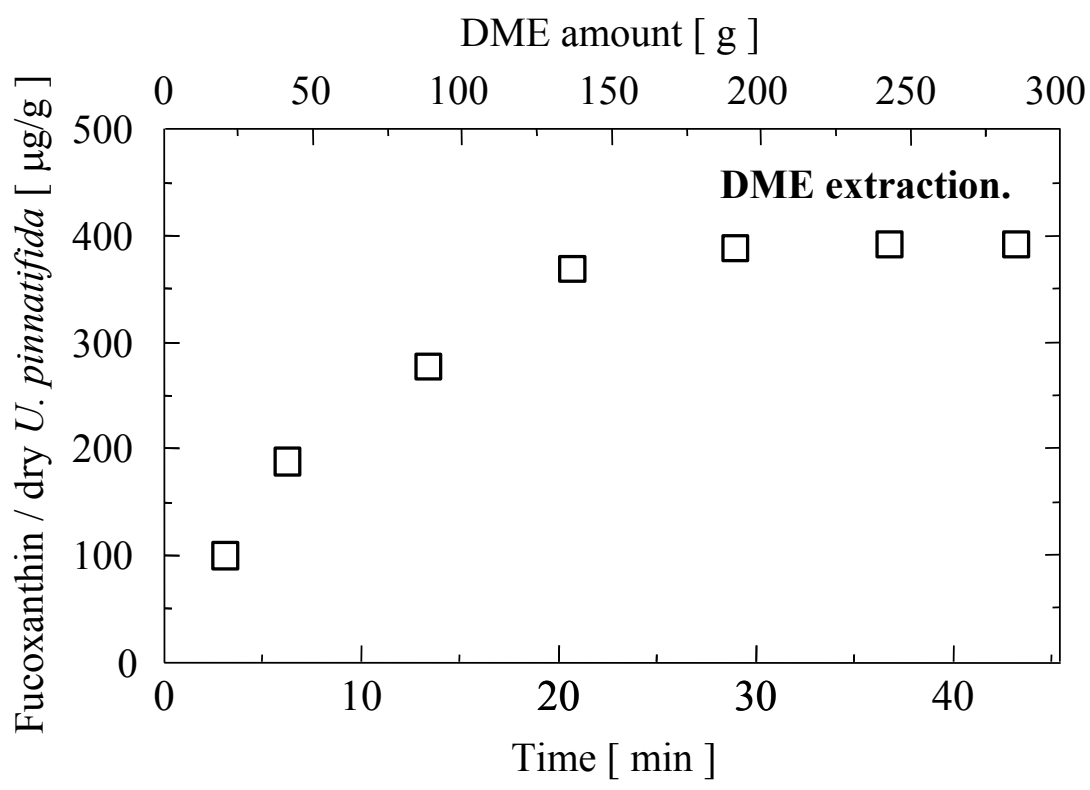

Compared with other, ethanol soxhlet, the fucoxanthin amount by liquefied DME was quite high. It is well known that liquefied DME could dissolve a wide range of polar and non-polar substances. They are also good solvents for many hydrogen-bonded substances. To dissolve hydrogen bonded substances, high solvation energy was needed to break the hydrogen bonds. In this case, DME has ability to act hydrogen bond acceptors, forming hydrogen bonds with hydrogen-bonding solutes. Therefore, liquefied DME can enter into $U$. pinnatifida cells and goes out together with $U$. pinnatifida 
components include fucoxanthin. In addition, the cumulative fucoxanthin extracted looks like complete after $191 \mathrm{~g}$ of DME consumption, however, the cumulative fucoxanthin extracted seemed clearly to be enhanced with increasing the DME consumption. As mentioned before, despite liquefied DME had high dissolving ability, liquefied DME could also generate a lower viscosity of the analytes in the matrix and, accordingly, a better diffusion rate of the solute from the solid phase to the solvent. Consequently, the fucoxanthin in $U$. pinnatifida might be extracted easily.

\subsection{Supercritical $\mathrm{CO}_{2}$ Extraction}

For supercritical $\mathrm{CO}_{2}$ extraction system, the extraction of fucoxanthin was performed in a semi-continuous flow-type. Physically, the appearance of the extracts was oily. In general, they increased with the increase of pressure at constant temperature. This tendency happened due to direct increase of density and hence solvating power of supercritical $\mathrm{CO}_{2}[35,36]$. Figure 2a,b showed the extraction curves of fucoxanthin from $U$. pinnatifida for different extraction times and under different conditions in terms of pressure $\left(10-40 \mathrm{MPa} ; 60^{\circ} \mathrm{C}\right)$ and temperatures $\left(40-70{ }^{\circ} \mathrm{C} ; 40 \mathrm{MPa}\right)$. Initially, the yield of fucoxanthin increased significantly up to $150 \mathrm{~min}$ extraction time. For example, the yield of fucoxanthin is about $47 \mu \mathrm{g} / \mathrm{g}$ dry weight of $U$. pinnatifida dried after $30 \mathrm{~min}$ at $40 \mathrm{MPa}$ and $60{ }^{\circ} \mathrm{C}$. Then, it increased gradually to $58 \mu \mathrm{g} / \mathrm{g}$ dry weight of $U$. pinnatifida at $150 \mathrm{~min}$ extraction time. Over 150 min extraction time, the yield of fucoxanthin was not increase significantly. At the same extraction temperature, the same trend was found at 10,20, and $30 \mathrm{MPa}$. As previously mentioned, the effect of pressure can be attributed to the increase in solvent power and by the strengthening of intermolecular physical interactions. It is also evident that an increase in pressure had effect on the solubility of fucoxanthin in supercritical $\mathrm{CO}_{2}$. This result is in agreement with similar trends reported by other authors [29,37]. Machmudah et al. reported that the total extract and the astaxanthin extracted were not significantly affected by the increasing pressure at 30-50 MPa, and after which the dramatic increase was observed at the pressure of $55 \mathrm{MPa}$. They explained that the dependency on the pressure was expected as the $\mathrm{CO}_{2}$ density increases at higher pressure, and therefore the solvent power to dissolve the substances increases [29]. At constant pressure (40 MPa), the yield of fucoxanthin also increased with increasing extraction temperature. It increased rapidly till $150 \mathrm{~min}$ extraction time then remained constant after 200 min extraction time in each extraction temperature. The highest extraction rate of fucoxanthin was reached when the extraction temperature is $60{ }^{\circ} \mathrm{C}$. The maximum fucoxanthin content obtained was $60 \mu \mathrm{g} / \mathrm{g}$ dry weight of $U$. pinnatifida after $270 \mathrm{~min}$ extraction time. As shown in the Figure $2 b$, the amount of fucoxanthin increased with an increase in temperature. These results indicated that the fucoxanthin extractions are dependent on solute vapor pressure which increased with an increase in temperature. Instead of that, the increasing temperature contributed to the decomposition of cell walls, and as a result fucoxanthin and extractable compounds availability for extraction was increased [29]. In addition, due to the fast extraction rate of fucoxanthin from $U$. pinnatifida, this figure also showed that an increase in temperature likely had a stronger effect on the solubility than an increase in pressure. At $70{ }^{\circ} \mathrm{C}$, the yield of fucoxanthin is lower than at $60{ }^{\circ} \mathrm{C}$. In this case, degradation of fucoxanthin might also take place, considering that carotenoids in general are considered to be heat-sensitive [33]. 
Figure 2. (a) Effect of pressures on the amount of fucoxanthin as a function of time at $60{ }^{\circ} \mathrm{C}$ of extraction temperature; (b) Effect of temperatures on the amount of fucoxanthin as a function of time at $40 \mathrm{MPa}$ of extraction pressure; (c) Effect of entrainer flow rate on the amount of fucoxanthin as a function of time at $60{ }^{\circ} \mathrm{C}$ and $40 \mathrm{MPa}$.

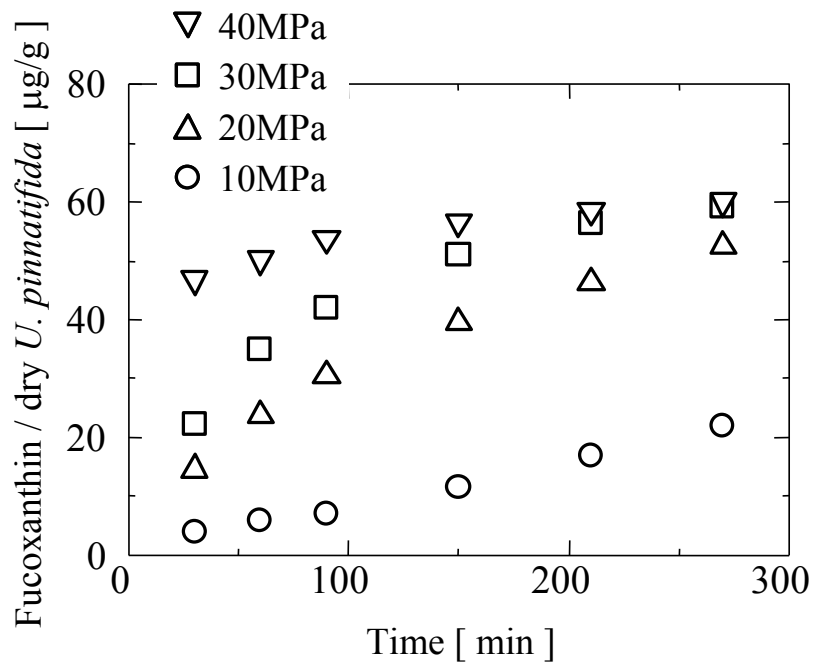

(a)

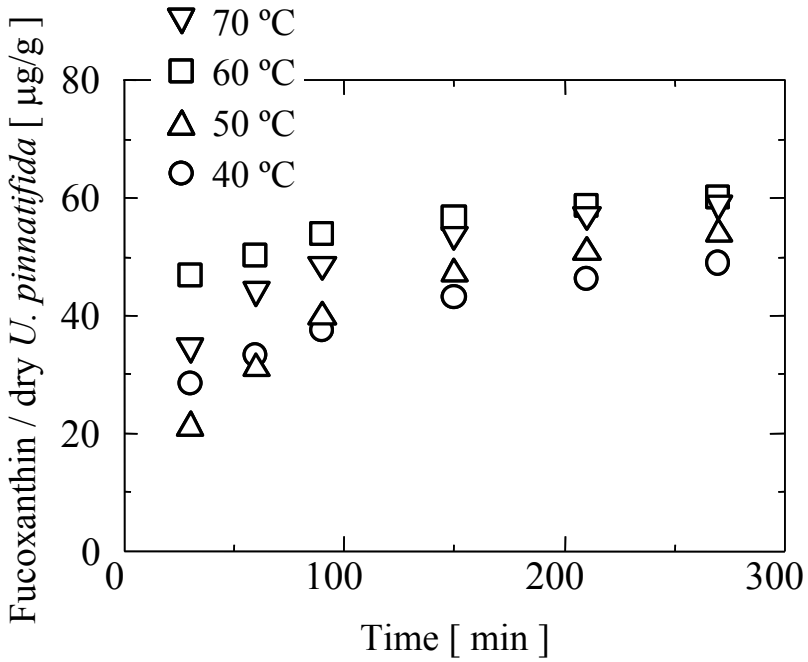

(b)

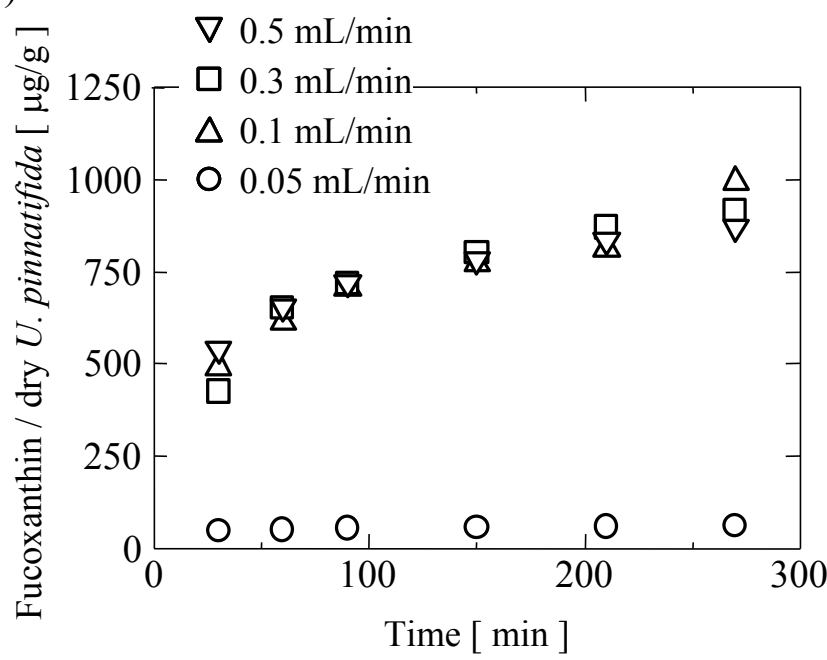

(c)

In this work, the amounts of fucoxanthin extracted by supercritical $\mathrm{CO}_{2}$ extraction with and without ethanol as entrainer were compared. The experiments were conducted under $60{ }^{\circ} \mathrm{C}$ and $40 \mathrm{MPa}$ with various entrainer concentrations $(1.64 \%-14.29 \%$ in volume). This condition was selected because at that condition the extraction rate of fucoxanthin was high. When the concentration of $1.67 \%$ ethanol was employed, there was no significant effect on the amount of fucoxanthin extracted. As shown in Figure 2c, the enhancement of ethanol concentration had high effect on the amount of fucoxanthin extracted. The recovery of fucoxanthin could reach 10 -fold. This considerable increase in extraction efficiency was because the ethanol added could enhance the solvent power of supercritical $\mathrm{CO}_{2}$ and caused swelling of the matrix, thus increasing the internal volume and the surface area for the contact with supercritical $\mathrm{CO}_{2}$ [29]. Machmudah et al. explained that the addition of ethanol in supercritical $\mathrm{CO}_{2}$ also could cause decomposition of the $\mathrm{H}$. pluvialis cellular wall, with the result that the astaxanthin availability for extraction increased [29]. 


\subsection{Comparison of the Results of Three Extraction Techniques}

As shown in Table 1, different extraction techniques, such as soxhlet, DME, and supercritical $\mathrm{CO}_{2}$ extraction have been used to isolate fucoxanthin from the $U$. pinnatifida plant, however none of them can be considered as an optimal method for this purpose. Except DME extraction technique, pre-treatment of $U$. pinnatifida, such as drying, was needed. The main disadvantages of soxhlet extraction are the long time required and the large amount of solvent wasted, which is costly and cause environmental problems. Due to the long extraction time at the boiling point of the ethanol solvent, the possible degradations of fucoxanthin due to local overheating effects might occur. This process was performed to disrupt the cell membrane in $U$. pinnatifida, thus extraction efficiency of fucoxanthin increases. Supercritical $\mathrm{CO}_{2}$ as known is attractive extraction method for food industries because the solvent is safe, nontoxic and easily removable, the method is fast and extraction parameters can be changed in a wide range of pressure and temperature. However, $\mathrm{CO}_{2}$ is non-polar fluid and it is the main disadvantage in its use for the isolation of antioxidants. As explained before, to improve the fucoxanthin yield, ethanol was introduced to increase the polarity of $\mathrm{CO}_{2}$. However, respecting to separation process, it is not only expensive but also difficult. On the contrary, the cell disruption of U. pinnatifida is not required when the DME was employed as extractant due to the properties of DME (see "Introduction"). That is why this technique of fucoxanthin extraction is very simple and versatile.

Table 1. Best recoveries of fucoxanthin obtained using different extraction techniques.

\begin{tabular}{ccccc}
\hline Extraction Techniques & Time $(\mathbf{h})$ & Temperature $\left({ }^{\circ} \mathbf{C}\right)$ & Pressure $(\mathbf{M P a})$ & Yield of Fucoxanthin $(\boldsymbol{\mu g} / \mathbf{g})$ \\
\hline Ethanol soxhlet & 12 & 78 & $*$ & 50 \\
Liquefied DME & 0.72 & 25 & $*$ & 390 \\
& 3 & 60 & 40 & 60.12 \\
Supercritical $\mathrm{CO}_{2}$ & 3 & 70 & 40 & 59.51 \\
Supercritical $\mathrm{CO}_{2}$ with & 3 & 60 & 40 & 994.53 \\
entrainer $(3.23 \%)$ & & & & \\
\hline
\end{tabular}

* not determined.

\section{Experimental Section}

\subsection{Materials}

U. pinnatifida was obtained from Fukui Prefecture, Japan and used as a starting material. Most of $U$. pinnatifida that did not meet strict quality standards are usually discarded as wastes, a situation, which is becoming an environmental concern. The appearance of $U$. pinnatifida is shown in Figure 3. The elemental composition of $U$. pinnatifida is given in Table 2. The apparatus of elemental analysis was conducted by a CHN analyzer (MT-6 Elemental analyzer, Yanaco New Science Inc., Kyoto, Japan) based on flash combustion, which converts all organic substances into combustion gases $\left(\mathrm{H}_{2} \mathrm{O}, \mathrm{CO}_{2}, \mathrm{~N}_{2}\right)$. DME and $\mathrm{CO}_{2}$ were purchased from Tamiya, Inc. Japan and Sogo Kariya Sanso, Inc. Japan, respectively. Fucoxanthin (94.0\%) purchased from Wako Pure Chemicals Industries Ltd. (Osaka, Japan) was used as standard. It was stored at $-60{ }^{\circ} \mathrm{C}$ in freezer (NF-75SF3, Nihon Freezer Co. Ltd., Tokyo, Japan). The analytical reagents used were acetonitrile, chloroform, and ethanol (HPLC-grade) from Wako Pure Chemicals Industries Ltd. (Osaka, Japan). All chemicals were used as received. 
Figure 3. Wet $U$. pinnatifida sample.

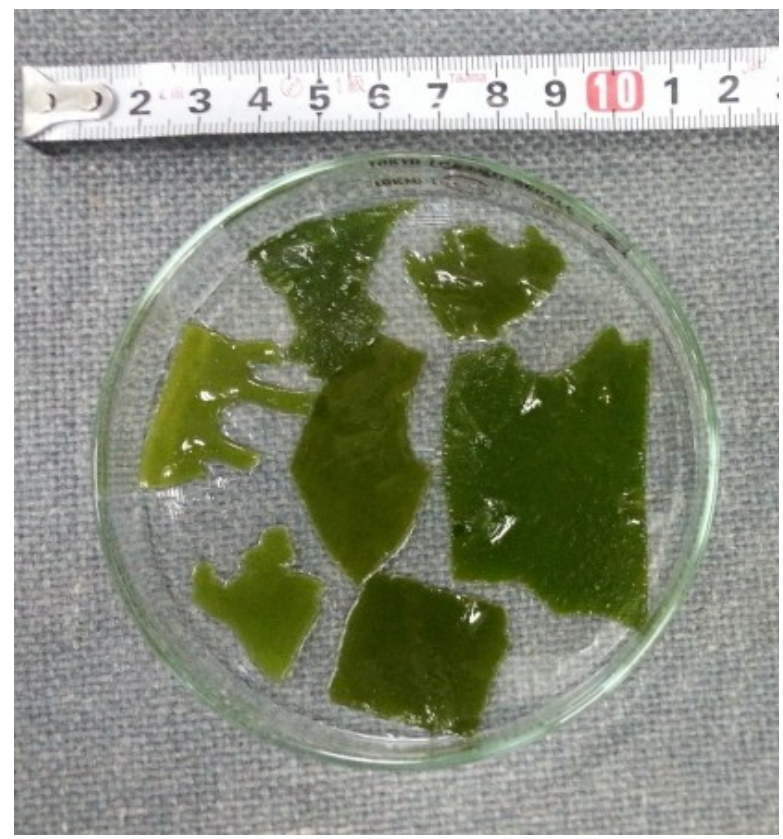

Table 2. Elemental analysis of $U$. pinnatifida by $\mathrm{CHN}$ analyzer, on average.

\begin{tabular}{ccccc}
\hline \multirow{2}{*}{ Materials } & \multicolumn{4}{c}{ Ultimate Analysis (wet weight\%, DAF) } \\
\cline { 2 - 5 } & $\mathbf{C ~ ( \pm 0 . 2 )}$ & $\mathbf{H}(\mathbf{\pm 0 . 1})$ & $\mathbf{N ~}( \pm \mathbf{0 . 1})$ & $\mathbf{O} * \mathbf{( \pm \mathbf { 0 . 3 } )}$ \\
\hline Original algae & 33.0 & 5.5 & 3.5 & 58.0 \\
Residue & 36.1 & 5.9 & 4.7 & 53.3 \\
Extract & 55.6 & 8.6 & 1.4 & 34.4 \\
\hline
\end{tabular}

* Oxygen content was determined by difference.

\subsection{Analytical Methods}

There are many carotenoids could be extracted from plant material. However, in this work, fucoxanthin was subjected as the target of carotenoid compounds recovery from $U$. pinnatifida, and determined quantitatively by using HPLC (high-performance liquid chromatography). The organic components in extracts were recovered with $2 \mathrm{~mL}$ of chloroform, and all the solutions were filtered using a disposable filter of $0.45 \mu \mathrm{m}$ pore size prior to HPLC analysis. The separation of fucoxanthin was carried out according to a previous published method [30] with modification. Initially, the pure compound of fucoxanthin dissolved in chloroform as a standard was injected in the HPLC system to construct calibration curve in 5 point. After separation process in the HPLC column, the amount of fucoxanthin leaving the column will determine the intensity of the signal produced in the detector. By comparing the time it takes for the peak to show up (the retention time) with the retention times for fucoxanhin, the amount of fucoxanthin in the extract can be identified (Figure 4). This analysis can be performed with good precision; therefore, other techniques analysis was not conducted. The HPLC instrument used was an ultraviolet-visible spectroscopy detector (UV-970; JASCO, Tokyo, Japan) equipped with an ODS-3 column (GL Sciences, Tokyo, Japan; $5 \mu \mathrm{m} ; 250 \mathrm{~mm} \times 4.6 \mathrm{~mm}$ ) and operated at $40{ }^{\circ} \mathrm{C}$. The mobile phase contained acetonitrile and water $(80 / 20, \mathrm{v} / \mathrm{v})$ with flow rate of $1.0 \mathrm{~mL} / \mathrm{min}$. Preparation of standard curve and detection were accomplished at wavelength of $445 \mathrm{~nm}$. 
Figure 4. HPLC chromatogram of fucoxanthin extract from U. pinnatifida.

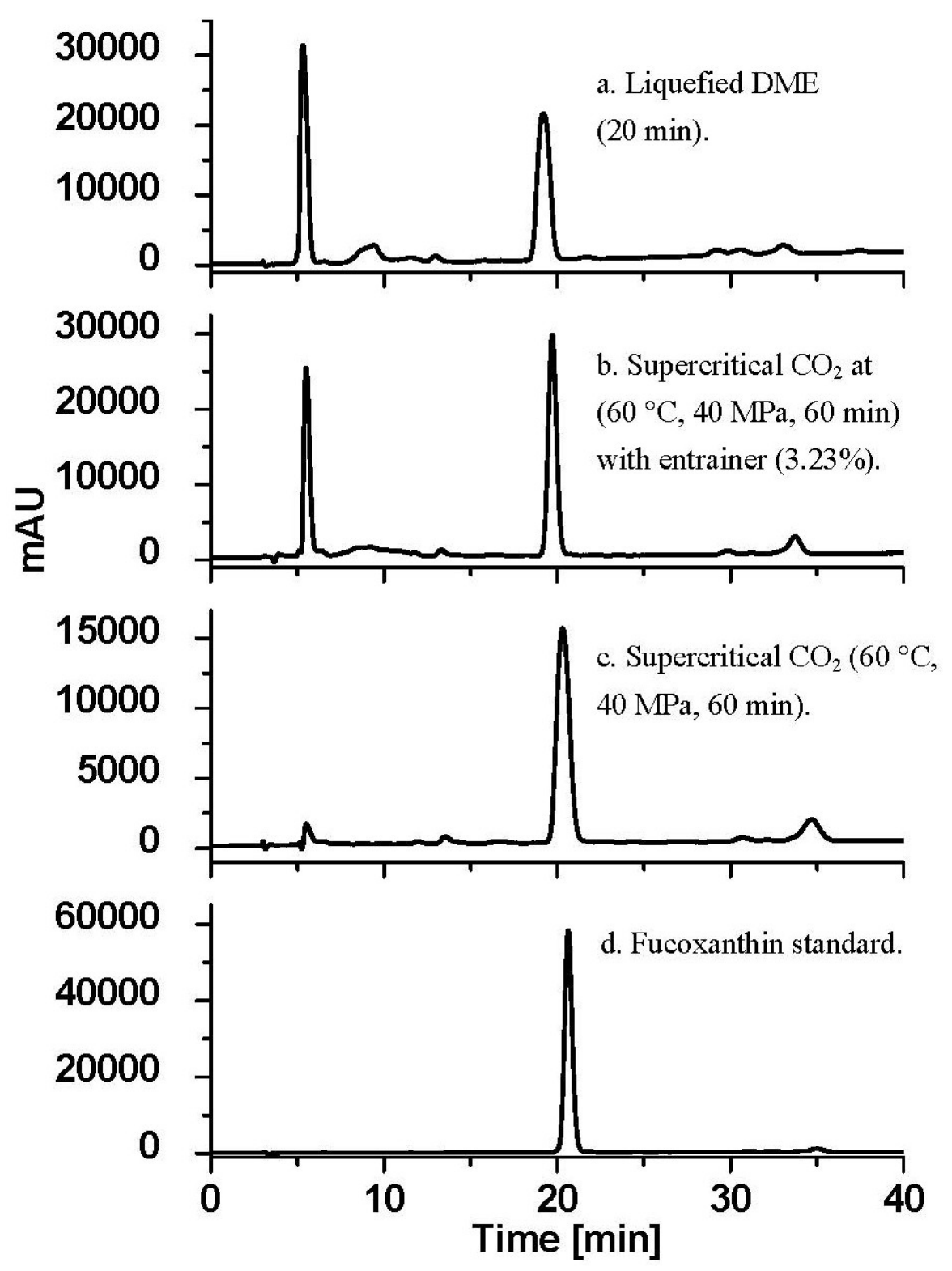

\subsection{Ethanol Soxhlet Extraction}

In this extraction, the heating mantle temperature was set at $78{ }^{\circ} \mathrm{C}$ for $12 \mathrm{~h}$. The amount of dried $U$. pinnatifida and ethanol used in flask were $6 \mathrm{~g}$ and $200 \mathrm{~mL}$, respectively. The flask was then removed from the mantle, and the liquid extracts were transferred to bottle that covered with aluminium foil and refrigerated until analysis. In this work (DME extraction, supercritical $\mathrm{CO}_{2}$ extraction and ethanol soxhlet extraction), the $U$. pinnatifida was fed without any pre-treatments such as microparticulation.

\subsection{DME Extraction}

Figure 5 depicted the apparatus scheme that used to evaluate the extraction efficiency of the DME extraction. The main apparatus consisted of extractor (HPG-10-5; Taiatsu Techno Corp., Saitama, Japan; volume: $10 \mathrm{~cm}^{3}$ ), needle valve to control the DME flow rate, and extract storage tank (HPG-96-3; 
Taiatsu Techno Corp., Saitama, Japan; volume: $96 \mathrm{~cm}^{3}$ ). Briefly, they were connected in series included feed materials. The extractor and DME storage tank were made of pressure-resistant glass coated with polycarbonate. $4.40 \mathrm{~g}$ of the raw U. pinnatifida (water content: $93.2 \%$ ) was loaded into the lower half of the extractor, and the upper half was loaded with colorless glass beads. The DME flow rate was $10 \pm 2 \mathrm{~cm}^{3} \mathrm{~min}^{-1}$. The extraction temperature and absolute pressure were $25 \pm 1{ }^{\circ} \mathrm{C}$ and $0.59 \pm 0.02 \mathrm{MPa}$, respectively. After passing liquefied DME through the extractor at different time intervals, the DME was evaporated by opening the reducing valve of the storage vessel. Next, liquefied DME pass through the lower half of extractor, color of glass beads in the upper half was changed to olive-green color. Because the glass beads and liquefied DME were colorless, the olive-green color indicated the probable presence of fucoxanthin. The extraction test was finished when the color of glass beads was changed again to colorless. The total time needed was less than 43 min.

Figure 5. Schematic diagram of DME extraction.

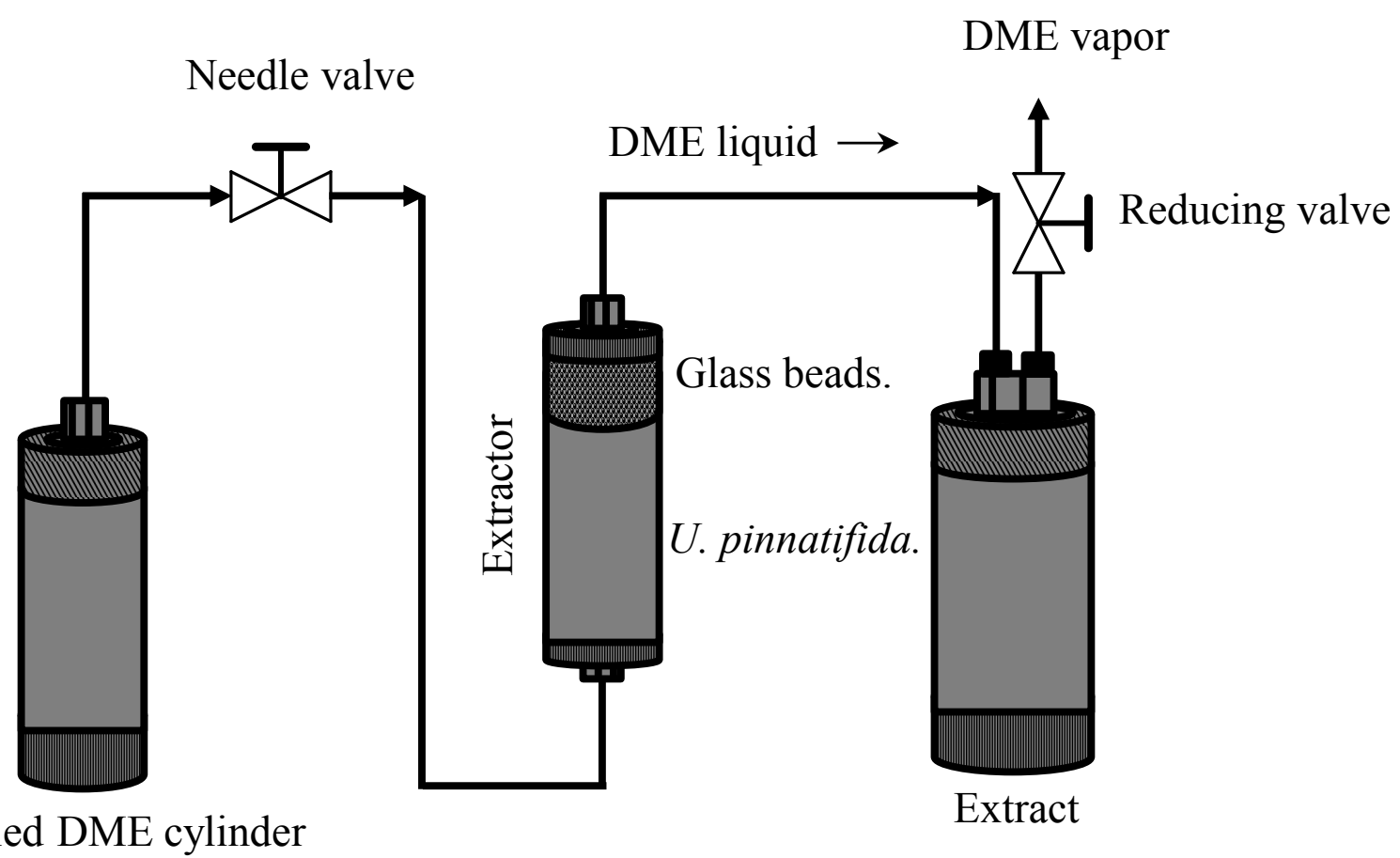

\subsection{Supercritical $\mathrm{CO}_{2}$ Extraction}

The supercritical $\mathrm{CO}_{2}$ extraction was carried out in an apparatus with schematic diagram as shown in Figure 6. The apparatus includes a high-pressure pump for $\mathrm{CO}_{2}$ (PU-2086; Jasco, Hachioji, Japan), a heating chamber (WFO-400; EYELA, Tokyo, Japan), a 25 mL extraction cell (Thar Technologies, Inc., Pittsburgh, PA, USA) and back pressure regulator (AKICO, Tokyo, Japan). In this work, the extraction of fucoxanthin from $U$. pinnatifida by supercritical $\mathrm{CO}_{2}$ was conducted at temperatures of $40-70{ }^{\circ} \mathrm{C}$ and pressures of 20-40 MPa using a semi-continuous flow-type system with $\mathrm{CO}_{2}$ flow rate of $3 \mathrm{~mL} \mathrm{~min}^{-1}$. In each experiment, $3.0 \mathrm{~g}$ of dry $U$. pinnatifida sample was loaded into the extraction vessel, filled with glass beads at the bottom and top of the extraction vessel. The extraction vessel was placed in the heating chamber to maintain the operating temperature. The extracts were collected every $1 \mathrm{~h}$ for $5 \mathrm{~h}$, weighed and analyzed immediately after collection. In all experiments, including ethanol soxhlet 
extraction and DME extraction, the extraction products were directly stored in the refrigerator at $-60{ }^{\circ} \mathrm{C}$. The bottles used for the collection of extracts were wrapped in aluminum foil. These processes were maintained until analysis. Co-solvent effect of ethanol on the supercritical $\mathrm{CO}_{2}$ extraction was also examined. Ethanol flow rates that supplied by using high-pressure pump (PU-2080; Jasco, Hachioji, Japan) were between 0.05 and $0.5 \mathrm{~mL} \mathrm{~min}^{-1}$. In the case of co-solvent used, the pressure and temperature selected were $40 \mathrm{MPa}$ and $60{ }^{\circ} \mathrm{C}$, respectively.

Figure 6. Schematic diagram of supercritical $\mathrm{CO}_{2}$ extraction.

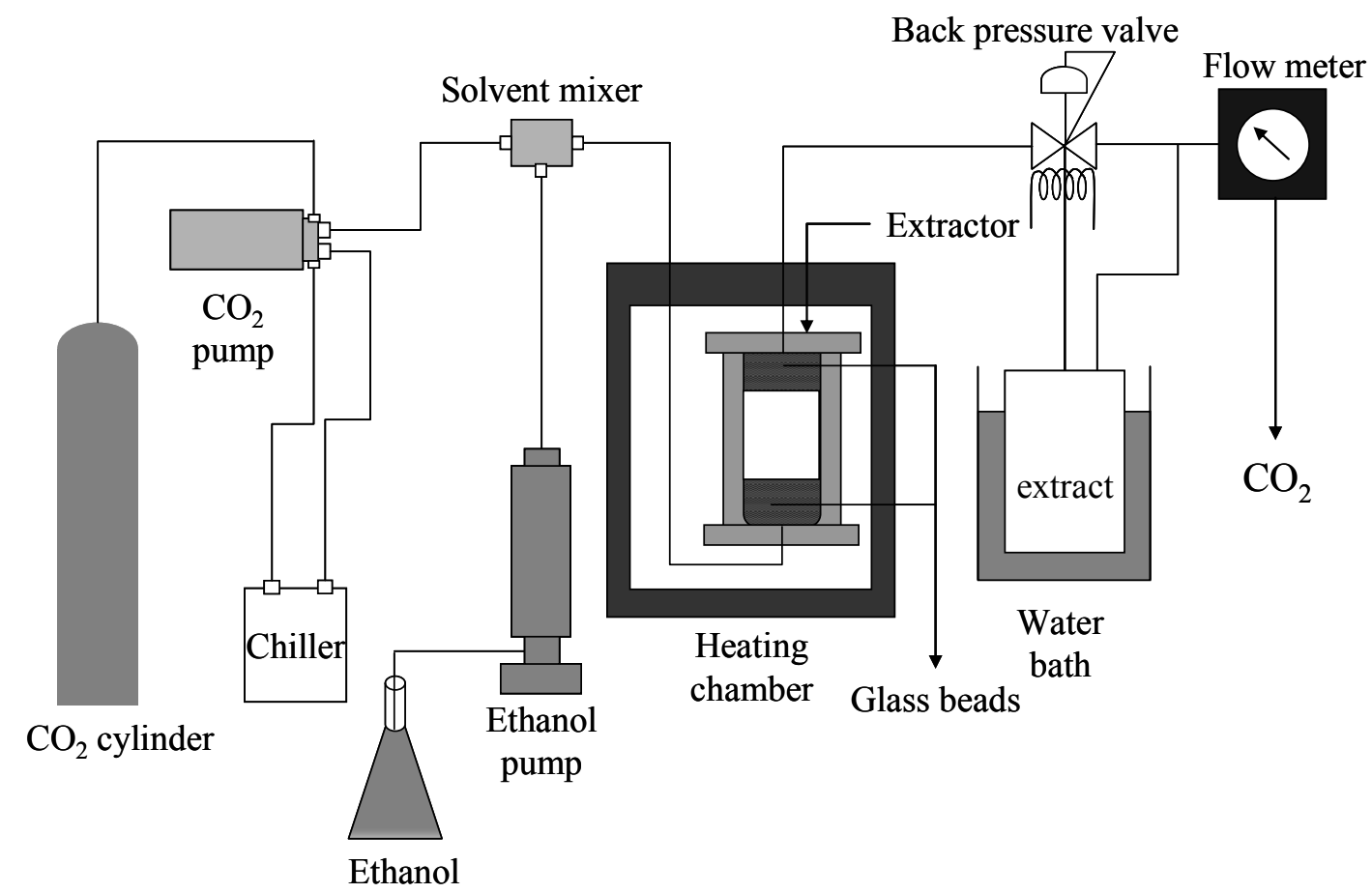

\section{Conclusions}

Liquefied DME extraction of fucoxanthin from $U$. pinnatifida was studied at temperature of $25{ }^{\circ} \mathrm{C}$ and pressure of $0.59 \mathrm{MPa}$ using a semi-continuous flow-type system, a simple and environmentally friendly extraction method. Under these conditions, DME has ability to act hydrogen bond acceptors, forming hydrogen bonds with hydrogen-bonding solutes. Therefore, liquefied DME can enter into $U$. pinnatifida cells and goes out together with $U$. pinnatifida components include fucoxanthin. The amount of fucoxanthin could approach to $390 \mu \mathrm{g} / \mathrm{g}$ dry $U$. pinnatifida when the amount of DME used was $286 \mathrm{~g}$. Compared with supercritical $\mathrm{CO}_{2}$ and ethanol Soxhlet extraction, the result was quite high. Thus, DME extraction process appears to be a good method for fucoxanthin recovery from $U$. pinnatifida with improved yields. On the basis of these results, it is proposed that DME extraction is applicable to isolate carotenoids from other types of biomass.

\section{Acknowledgments}

A part of this research was supported by a grant from the Precursory Research for Embryonic Science and Technology Program of Japan Science and Technology Agency. 


\section{Author Contributions}

Kanda, H.: responsible to research publication, Kamo, Y.: carried out the experiment, Machmudah, S. and Wahyudiono: conducted all data analyses, Goto, M.: supervised this work and provided all experimental and analytical equipment. All authors read and approved the final manuscript.

\section{Conflicts of Interest}

The authors declare no conflict of interest.

\section{References}

1. Maeda, H.; Hosokawa, M.; Sashima, T.; Funayama, K.; Miyashita, K. Fucoxanthin from edible seaweed, Undaria pinnatifida, shows antiobesity effect through UCP1 expression in white adipose tissues. Biochem. Biophys. Res. Commun. 2005, 332, 392-397.

2. Yan, X.; Chuda, Y.; Suzuki, M.; Nagata, T. Fucoxanthin as the major antioxidant in Hijikia fusiformis, a common edible seaweed. Biosci. Biotechnol. Biochem. 1999, 63, 605-607.

3. Jung, H.A.; Islam, M.N.; Lee, C.M.; Jeong, H.O.; Chung, H.Y.; Woo, H.C.; Choi, J.S. Promising antidiabetic potential of fucoxanthin isolated from the edible brown algae Eisenia bicyclis and Undaria pinnatifida. Fish. Sci. 2012, 78, 1321-1329.

4. Maeda, H.; Hosokawa, M.; Sashima, T.; Miyashita, K. Dietary combination of fucoxanthin and fish oil attenuates the weight gain of white adipose tissue and decreases blood glucose in obese/diabetic KK-A ${ }^{\mathrm{y}}$ mice. J. Agric. Food Chem. 2007, 55, 7701-7706.

5. Beppu, F.; Hosokawa, M.; Niwano, Y.; Miyashita, K. Effects of dietary fucoxanthin on cholesterol metabolism in diabetic/obese KK-A ${ }^{\mathrm{y}}$ mice. Lipids Health Dis. 2012, 11, 112-119.

6. Hu, X.; Li, Y.; Li, C.; Fu, Y.; Cai, F.; Chen, Q.; Li, D. Combination of fucoxanthin and conjugated linoleic acid attenuates body weight gain and improves lipid metabolism in high-fat diet-induced obese rats. Arch. Biochem. Biophys. 2012, 519, 59-65.

7. Fung, A.; Hamid, N.; Lu, J. Fucoxanthin content and antioxidant properties of Undaria pinnatifida. Food Chem. 2013, 136, 1055-1062.

8. Sachindra, N.M.; Sato, E.; Maeda, H.; Hosokawa, M.; Niwano, Y.; Kohno, M.; Miyashita, K. Radical scavenging and singlet oxygen quenching activity of marine carotenoid fucoxanthin and its metabolites. J. Agric. Food Chem. 2007, 55, 8516-8522.

9. Hosokawa, M.; Kudo, M.; Maeda, H.; Kohno, H.; Tanaka, T.; Miyashita, K. Fucoxanthin induces apoptosis and enhances the antiproliferative effect of the PPAR $\gamma$ ligand, troglitazone, on colon cancer cells. Biochim. Biophys. Acta 2004, 1675, 113-119.

10. Kotake-Nara, E.; Kushiro, M.; Zhang, H.; Sugawara, T.; Miyashita, K.; Nagao, A. Carotenoids affect proliferation of human prostate cancer cells. J. Nutr. 2002, 131, 3303-3306.

11. Shiratori, K.; Ohgami, K.; Ilieva, I.; Jin, X.-H.; Koyama, Y.; Miyashita, K.; Yoshida, K.; Kase, S.; Ohno, S. Effects of fucoxanthin on lipopolysaccharide-induced inflammation in vitro and in vivo. Exp. Eye Res. 2005, 81, 422-428. 
12. Plaza, M.; Cifuentes, A.; Ibanez, E. In the search of new functional food ingredients from algae. Trends Food Sci. Technol. 2008, 19, 31-39.

13. Shang, Y.F.; Kim, S.M.; Lee, W.J.; Um, B.-H. Pressurized liquid method for fucoxanthin extraction from Eisenia bicyclis (Kjellman) Setchell. J. Biosci. Bioeng. 2011, 111, 237-241.

14. Plaza, M.; Santoyo, S.; Jaime, L.; Garcia-Blairsy, R.G.; Herrero, M.; Senorans, F.J.; Ibanez, E. Screening for bioactive compounds from algae. J. Pharm. Biomed. Anal. 2010, 51, 450-455.

15. Xiao, X.; Si, X.; Yuan, Z.; Xu, X.; Li, G. Isolation of fucoxanthin from edible brown algae by microwave-assisted extraction coupled with high-speed countercurrent chromatography. J. Sep. Sci. 2012, 35, 2313-2317.

16. Halim, R.; Harun, R.; Danquah, M.K.; Webley, P.A. Microalgal cell disruption for biofuel development. Appl. Energy 2012, 91, 116-121.

17. Halim, R.; Danquah, M.K.; Webley, P.A. Extraction of oil from microalgae for biodiesel production: A review. Biotechnol. Adv. 2012, 30, 709-732.

18. Halim, R.; Rupasinghe, T.W.T.; Tull, D.L.; Webley, P.A. Mechanical cell disruption for lipid extraction from microalgal biomass. Bioresour. Technol. 2013, 140, 53-63.

19. Hii, S.-L.; Choong, P.-Y.; Woo, K.-K.; Wong, C.-L. Stability studies of fucoxanthin from Sargassum Binderi. Aust. J. Basic Appl. Sci. 2010, 4, 4580-4584.

20. Billakanti, J.M.; Catchpole, O.; Fenton, T.; Mitchell, K. Extraction of fucoxanthin from Undaria pinnatifida using enzymatic pre-treatment followed by DME and EtOH co-solvent extraction. In Proceedings of the 10th International Symposium on Supercritical Fluids, San Fransisco, CA, USA, 13-16 May 2012; King, J., Ed.; CASSS: Emeryville, CA, USA, 2012.

21. Wu, J.; Zhou, Y.; Lemmon, E.W. An equation of state for the thermodynamic properties of dimethyl ether. J. Phys. Chem. Ref. Data 2011, 40, 023104.

22. Eltringham, W.; Catchpole, O.J. Relative permittivity measurements of gaseous, liquid, and supercritical dimethyl ether. J. Chem. Eng. Data 2007, 52, 363-367.

23. Holldorff, H.; Knapp, H. Binary vapor-liquid-liquid equilibrium of dimethyl ether-water and mutual solubilities of methyl chloride and water: Experimental results and data reduction. Fluid Phase Equilibria 1988, 44, 195-209.

24. European Food Safety Autorithy. Scientific opinion of the panel on food contact materials, enzymes, flavourings and processing aids (CEF) on dimethyl ether as an extraction solvent. EFSA J. 2009, 984, 1-13.

25. Varlet, V.; Smith, F.; Augsburger, M. New trends in the kitchen: Propellants assessment of edible food aerosol sprays used on food. Food Chem. 2014, 142, 311-317.

26. Naito, M.; Radcliffe, C.; Wada, Y.; Hoshino, T.; Liu, X.; Arai, M.; Tamura, M. A comparative study on the autoxidation of dimethyl ether (DME) comparison with diethyl ether (DEE) and diisopropyl ether (DIPE). J Loss Prev. Process Ind. 2005, 18, 469-473.

27. Li, P.; Kanda, H.; Makino, H. Simultaneous production of bio-solid fuel and bio-crude from vegetal biomass using liquefied dimethyl ether. Fuel 2014, 116, 370-376.

28. Mendes, R.L.; Fernandes, H.L.; Coelho, J.P.; Reis, E.C.; Cabral, J.M.S.; Novais, J.M.; Palavra, A.F. Supercritical $\mathrm{CO}_{2}$ extraction of carotenoids and other lipids from Chlorella vulgaris. Food Chem. 1995, 53, 99-103. 
29. Machmudah, S.; Shotipruk, A.; Goto, M.; Sasaki, M.; Hirose, T. Extraction of Astaxanthin from Haematococcus pluvialis using supercritical $\mathrm{CO}_{2}$ and ethanol as entrainer. Ind. Eng. Chem. Res. 2006, 45, 3652-3657.

30. Kitada, K.; Machmudah, S.; Sasaki, M.; Goto, M.; Nakashima, Y.; Kumamoto, S.; Hasegawa, T. Supercritical $\mathrm{CO}_{2}$ extraction of pigment components with pharmaceutical importance from Chlorella vulgaris. J. Chem. Technol. Biotechnol. 2009, 84, 657-661.

31. Roh, M.K.; Uddin, M.S.; Chun, B.S. Extraction of fucoxanthin and polyphenol from Undaria pinnatifida using supercritical carbon dioxide with co-solvent. Biotechnol. Bioprocess Eng. 2008, 13, 724-729.

32. Richter, B.E.; Jones, B.A.; Ezell, J.L.; Avdalovic, N.; Pohl, C. Accelerated solvent extraction: A technique for sample preparation. Anal. Chem. 1996, 68, 1033-1039.

33. Kim, S.M.; Jung, Y.J.; Kwon, O.N.; Cha, K.H.; Um, B.H.; Chung, D.; Pan, C.H. A potential commercial source of fucoxanthin extracted from the microalga Phaeodactylum tricornutum. Appl. Biochem. Biotechnol. 2012, 166, 1843-1855.

34. Kanazawa, K.; Ozaki, Y.; Hashimoto, T.; Das, S.K.; Matsushita, S.; Hirano, M.; Okada, T.; Komoto, A.; Mori N.; Nakatsuka, M. Commercial-scale preparation of biofunctional fucoxanthin from waste parts of brown sea algae Laminalia japonica. Food Sci. Technol. Res. 2008, 14, 573-582.

35. Bai, S.; Craig, M.V.; Liu, L.F.; Mayne, C.L.; Pugmire, R.J.; Grant, D.M. $\mathrm{CO}_{2}$ clustering of 1-decanol and methanol in supercritical fluids by ${ }^{13} \mathrm{C}$ nuclear spin-lattice relaxation. J. Phys. Chem. 1997, 101, 2923-2928.

36. Bulgarevicg, D.S.; Sako, T.; Sujeta, T.; Otake, K.; Takebayashi, Y.; Kamizawa, C.; Horikawa, Y.; Kato, M. The role or general hydrogen-bonding interaction in the solvation process of organic compounds by supercritical $\mathrm{CO}_{2} / n$-alcohol mixtures. Ind. Eng. Chem. Res. 2002, 41, 2074-2081.

37. Nehari, A.A.; Kim, S.B.; Lee, Y.B.; Lee, H.T.; Chun, B.S. Characterization of oil including astaxanthin extracted from krill (Euphausia superba) using supercritical carbon dioxide and organic solvent as comparative method. Korean J. Chem. Eng. 2012, 29, 329-336.

(C) 2014 by the authors; licensee MDPI, Basel, Switzerland. This article is an open access article distributed under the terms and conditions of the Creative Commons Attribution license (http://creativecommons.org/licenses/by/3.0/). 